\title{
L'examen pour les experts en radioprotection? Sur Internet, tout simplement!
}

\author{
Examen sur Internet pour les experts en radioprotection
}

Office fédéral de la santé publique

L'année prochaine, certains médecins devront justifier de leur compétence d'expert en radioprotection. L'OFSP offre une solution rapide, simple et confortable: de février à juin 2004, il sera possible de passer cet examen de chez soi, en ligne.

Les médecins ayant obtenu l'autorisation d'exploiter une installation radiologique avant le $1^{\text {er }}$ octobre 1994 seront réputés experts jusqu'au 30 septembre 2004. Si l'installation radiologique est encore utilisée au delà de cette date, la compétence d'expert doit être justifiée au moyen d'un examen, ainsi que le prévoit l'ordonnance sur la radioprotection.

Pour des raisons pratiques, l'Office fédéral de la santé publique (OFSP), à la demande de la FMH, offre la possibilité de passer l'examen sur un ordinateur, en ligne, de début février à fin juin 2004. Pour ce faire, il faut avoir un accès Internet et une adresse électronique. Ces examens sont mis en place par PNN SA, une société autonome (spin-off) de l'EPFZ spécialisée dans la formation médicale continue en ligne. Le «Manuel pour les experts en radioprotection dans les domaines médicaux» (Philipp R. Trueb [éd.], ISBN 3-258-06494-6) constitue l'ouvrage de référence pour se préparer. Les frais d'examen s'élèvent à 150 francs.
Les médecins qui souhaitent passer cet examen sur Internet pourront s'inscrire dès février 2004 sur le site www.str-rad.ch. L'OFSP examinera la recevabilité de leur demande et leur enverra par courriel, dans les plus brefs délais (trois semaines au maximum), un code d'enregistrement personnel. Dès lors, il sera possible de commencer.

Une fois le code d'accès entré, il sera tout d'abord possible de se familiariser avec la navigation en effectuant un test blanc recouvrant un autre domaine. Les candidats disposeront ensuite de 60 minutes exactement pour répondre aux questions à choix multiples. En outre, ils pourront interrompre le test deux fois en l'espace de 24 heures, à condition que les 60 minutes ne soient pas écoulées.

Immédiatement près avoir passé le test, les candidats reçoivent un message, à titre indicatif, leur signalant s'ils ont atteint les $60 \%$ requis. Par la suite, l'OFSP enverra un certificat à ceux qui ont réussi. Les personnes qui ont échoué recevront une notification écrite et obtiendront sans frais supplémentaires une chance pour repasser l'examen en ligne.

L'OFSP espère que la plupart des médecins choisiront cette formule et souhaite bonne chance à tous les candidats. 